\title{
OS DIREITOS POLÍTICOS DO PRESO PROVISÓRIO: UMA ANÁLISE DA (IM) POSSIBILIDADE DO VOTO.
}

\begin{abstract}
Resumo: O objetivo desta pesquisa, realizada por meio de revisão bibliográfica e levantamento de dados, é verificar a possibilidade de manutenção dos direitos políticos do preso provisório. Primeiro, apresenta-se uma análise das espécies de prisão e, em seguida, faz-se uma análise dos dados recentes sobre a população carcerária brasileira, para que, ao final, seja verificado se o preso provisório possui ou não direitos políticos, especialmente o direito ao voto e o impacto na democracia. Conclui-se que a Resolução no 23.129/2010 do TSE está em desacordo com a $\mathrm{CF} / 88$ por criar aspectos formais de limitação do acesso ao voto do preso provisório
\end{abstract}

Palavras-Chave: Democracia. Voto. Prisão Preventiva. Direitos Políticos. Direito Eleitoral.

\section{THE POLITICAL RIGHTS OF THE PROVISIONAL PRISONER: AN ANAL YSIS OF THE (IM) POSSIBILITY OF VOTING.}

Abstract: The objective of this academic research, through bibliographical review and analysis of empirical data, is to verify the maintenance of the political rights of provisional prisoners. First, an analysis of the types of prison is presented and then an analysis of the most recent data on the Brazilian prison population so that, in the end, the existence of the political rights and their impact in democracy can be verified. It's concluded that Resolution 23.129/2010 of the TSE is in disagreement with the Federal Constitution of 1988 for creating formal aspects of limiting the access to vote of the provisional prisoner.

Keywords: Democracy. Vote. Preventive Arrest. Political Rights. Electoral Law.

\footnotetext{
${ }^{1}$ Professor. Mestrando em Direito pela UNICHRISTUS. Pós-graduado em Direito Penal e Processual Penal pela Universidade Estadual do Ceará (UECE). Advogado. Bacharel em Direito Universidade de Fortaleza (UNIFOR). joserangeljr@gmail.com

2 Professor. Mestrando em Direito pela UNICHRISTUS. Pós-graduado em Direito Processual Civil pela Universidade de Fortaleza. Advogado. Bacharel em Direito pelo Centro Universitário Estácio do Ceará.adrianonobrega@outlook.com
} 


\section{INTRODUÇÃO.}

A população carcerária no Brasil é uma das maiores do mundo, ultrapassando a marca de 700.000 (setecentos mil) presos, entre presos definitivos e presos provisórios, no ano de 2016. (DEPEN, 2016). O percentual de presos provisórios dentro do sistema carcerário é de, aproximadamente, 40\% (DEPEN, 2016).

A prisão provisória permite a restrição de certos direitos previstos na Constituição Federal de 1988, mas alguns desses direitos não são, efetivamente, exercidos, como é o caso do direito ao voto, o qual só pode ser suspenso com o trânsito em julgado de sentença penal condenatória, nos termos do artigo $15^{\circ}$, inciso III da CF/88.

Apenas em 2010, o TSE editou a Resolução no 23.219 , determinando a criação de seções especiais de votação para os presos provisórios e os adolescentes internados, no entanto, a maioria dos Estados não conseguiu assegurar esse direito às pessoas com liberdade segregada. A supressão desse direito afiançado constitucionalmente ao preso provisório acaba por marginalizá-lo ainda mais, uma vez que, materialmente, o equipara ao preso condenado, além de excluí-lo do processo democrático de escolha dos representantes políticos.

Considerando que a população carcerária é extremamente marginalizada, a retirada do direito político ao voto do preso provisório acarreta um isolamento ainda maior, uma vez que os candidatos aos cargos proporcionais (principalmente) e majoritários acabem por não colocar em suas plataformas eleitorais propostas no sentido de melhorar a situação dessa população específica.

Com a finalidade de analisar a situação da prisão cautelar e do direito ao voto, partese do seguinte questionamento: a supressão do direito ao voto do preso provisório acaba por marginalizá-lo ainda mais, uma vez que o exclui do processo democrático eleitoral, ou é uma mera consequência da situação em que o indivíduo se encontra? Para responder tal questionamento, pretende-se aplicar uma pesquisa bibliográfica e documental, por meio da leitura de livros, artigos, legislação e jurisprudência, notadamente a Resolução no 23.219 do Tribunal Superior Eleitoral, pertinentes ao trabalho de pesquisa, bem como realizar uma análise empírica referente aos dados do sistema carcerário atual.

No intuito de perquirir os objetivos aqui delineados, além desta seção, o artigo será dividido numa parte que trata da prisão no Brasil, momento em que será verificada a diferença entre prisão processual e prisão penal, conhecida, majoritariamente, como prisão provisória e prisão definitiva. Empós, far-se-á um levantamento de dados da população carcerária brasileira, 
com o intuito de analisar a quantidade de presos existentes no sistema penitenciário. Na seção que antecede as notas conclusivas, verificar-se-ão os direitos políticos do preso no Brasil, com o intuito de constatar se, caso o preso provisório não exerça seu direito de voto, ocorre ilegalidade ou afronta às normas constitucionais.

\section{A PRISÃO NO BRASIL: UMA ANÁLISE DAS ESPÉCIES PREVISTAS NO ORDENAMENTO JURÍDICO.}

A Constituição Federal brasileira consagra, no inciso VCII do artigo 5º a presunção de inocência como princípio norteador do processo penal pátrio, especialmente quando afirma que "ninguém será considerado culpado até o trânsito em julgado de sentença penal condenatória” (BRASIL, 1988). Nesse sentido, como regra, a prisão de alguém só deve ser decretada após o trânsito em julgado de uma sentença penal condenatória.

É verdade que a própria Constituição Federal não veda a possibilidade de se decretar uma prisão sem que o processo de conhecimento tenha chegado ao fim, como se depreende do disposto no inciso LXI do artigo $5^{0}$ "ninguém será preso senão em flagrante delito ou por ordem escrita e fundamentada de autoridade judiciária competente” (BRASIL, 1988).

Desse modo:

Prisão é a privação da liberdade, tolhendo-se o direito de ir e vir, por meio do recolhimento da pessoa humana ao cárcere. A prisão pena advém da imposição de sentença condenatória com trânsito em julgado. A prisão cautelar é fruto da necessidade de se obter uma investigação ou instrução criminal produtiva, eficiente, livre de interferências. Embora ambas provoquem a segregação do indiciado ou acusado, a primeira constitui efetiva sanção penal; a segunda não passa de uma medida de cautela, com o fim de assegurar algo. Não é um fim, mas um meio. (NUCCI, 2012, p. 28-29).

Surge, então, a necessidade de diferenciar, conceitualmente, a espécie de prisão, com base na sua natureza jurídica, podendo classificá-la como prisão processual e prisão penal.

\subsection{Prisão Processual}

A prisão processual está autorizada constitucionalmente, mas dever ser encarada como exceção, só podendo ser decretada em situações em que o processo penal precise ser garantido. 
Assim, para que uma prisão processual possa ser decretada legal e legitimamente ${ }^{3}$, fazse necessária a presença dos requisitos cautelares, denominados no processo penal de fumus commissi delicti e periculum libertatis.

Sobre o tema, Lopes Jr. afirma que:

\begin{abstract}
No processo penal, o requisito para a decretação de uma medida coercitiva não é a probabilidade de existência do direito de acusação alegado, mas sim de um fato aparentemente punível. Logo, o correto é afirmar que o requisito para decretação de uma prisão cautelar é a existência do fumus commissi delicti, enquanto probabilidade da ocorrência de um delito (e não de um direito), ou, mais especificamente, na sistemática do CPP, a prova da existência do crime e indícios suficientes de autoria (...) O risco no processo penal decorre da situação de liberdade do sujeito passivo. Basta afastar a conceituação puramente civilista para ver que o periculum in mora no processo penal assume o caráter de perigo ao normal desenvolvimento do processo (perigo de fuga, destruição da prova) em virtude do estado de liberdade do sujeito passivo. Logo, o fundamento é um periculum libertatis, enquanto perigo que decorre do estado de liberdade do imputado. (LOPES JR., 2016, p. 599-600).
\end{abstract}

A prisão processual (provisória), como tutela cautelar que é, apresenta algumas características elencadas pela doutrina moderna, são elas: a instrumentalidade hipotética, acessoriedade, preventividade, sumariedade e provisoriedade. Desse modo, não deve existir prisão processual com a finalidade de apenar o acusado, mas tão somente de garantir a existência do processo penal, bem como que este transcorra de modo incólume aos interesses alheios, ou seja, a prisão provisória é, de fato, uma garantia que resguarda tão somente o direito processual, sem atingir o direito material dos agentes envolvidos.

Segundo Badaró:

A prisão processual será um instrumento para assegurar o resultado de uma hipotética condenação; não é um fim em si mesmo; sua finalidade é prevenir a ocorrência de um dano irreparável; seus efeitos perdurarão até a superveniência de um evento sucessivo e a tutela cautelar não se baseia em um juízo de certeza. (BARDARÓ, 2015, p. 938/940).

A prisão processual, portanto, restringe apenas alguns direitos, notadamente aqueles incompatíveis com a situação de pessoa encarcerada, como, por exemplo, o direito de ir e vir.

\footnotetext{
${ }^{3}$ Para a presente pesquisa, compreende-se a existência de legalidade quando há previsão no ordenamento jurídico e legitimidade quando determinada decisão preenche todos os requisitos necessários.
} 


\subsection{Prisão Penal}

Conforme analisado anteriormente, a prisão penal é aquela decorrente de uma sentença penal condenatória com trânsito em julgado, nos termos do inciso LVII, artigo $5^{\circ}$ da Constituição Federal de 1988. Isto é:

Por meio da sentença o juiz criminal julga definitivamente o mérito da pretensão penal, resolvendo-o em todas as suas etapas possíveis, a saber: a da imputação da existência de um fato (materialidade), a imputação da autoria desse fato e, por fim, o juízo de adequação ou valoração jurídico-penal da conduta. (PACELLI, 2013, p. 643).

Com o trânsito em julgado da sentença penal condenatória, além dos efeitos penais da condenação previstos nos artigos $91^{\circ}$ e $92^{\circ}$ do Código Penal, a Constituição Federal determina a suspensão dos direitos políticos, dentre eles, o de votar e ser votado:

Art. 15. É vedada a cassação de direitos políticos, cuja perda ou suspensão só se dará nos casos de:

(...)

III - condenação criminal transitada em julgado, enquanto durarem seus efeitos. (BRASIL, 1988).

Desta feita, apenas a sentença criminal de natureza condenatória e com trânsito em julgado tem o condão de determinar a perda ou a suspensão dos direitos políticos. Portanto, não há previsão, no ordenamento jurídico brasileiro, de suspender ou limitar os direitos políticos dos presos provisórios, apesar disso, há uma grande limitação ou, em alguns casos, completa ausência da participação desse preso na escolha dos representantes políticos.

\section{UM BREVE PANORAMA DA POPULAÇÃO CARCERÁRIA BRASILEIRA.}

O sistema penitenciário brasileiro, atualmente, tem grandes dificuldades estruturais e organizacionais, dentre elas, têm-se a superlotação nos presídios, as péssimas condições sanitárias, a má qualidade dos alimentos fornecidos, o descaso quanto à assistência médica, além da precária assistência judiciária, educacional e profissionalizante (PACI, 2014), tudo isso contribui para a não ressocialização do preso quando este termina de cumprir sua pena. 
É nessa sistemática que os meios de comunicação têm mostrado que, os presos, por meio de rebeliões, estão reivindicando e, ao mesmo tempo, denunciando as situações apresentadas acima, tendo como agravante de tudo isso a superlotação dos presídios. Em virtude do excesso humano nos presídios, o Estado não consegue fornecer, de modo satisfatório, os instrumentos mínimos para garantir os Direitos Humanos ${ }^{4}$ do preso.

Segundo René Ariel Dotti, as consequências dessas rebeliões ultrapassam os muros dos presídios para atingir a sociedade:

As rebeliões carcerárias desde há muito tempo deixaram de ser um problema localizado, no interior dos muros, para assumirem proporção de terror comunitário quando se multiplicam as vítimas dos sequestros impostos como condição para se efetivar garantias constitucionais e legais. Há uma nova legião de reféns nesses conflitos fabricados pela anomia e pela desesperança. Além dos guardas de presídios - os involuntários parceiros dessas rotas de fuga - a vitimidade de massa envolve outros atores: os dirigentes e técnicos dos estabelecimentos penais e os familiares dos presos. Até mesmo crianças, levadas pelas mãos calejadas das mulheres para a visita semanal, fazem parte dessa cadeia de novos flagelados da violência institucional e privada. (DOTTI, 1999).

Essas atitudes violentas nos presídios e na sociedade, cujo condão é a reivindicação de melhores condições no cárcere, surgem porque, embora exista uma vasta legislação que assegura aos detentos os Direitos e garantias fundamentais, a realidade se mostra em confronto com todos estes direitos. De fato, as garantias e direitos fundamentais restam inertes na dogmática jurídica, enquanto as análises empíricas da situação social e jurídica dos presos mostram que, em sua grande maioria, estes indivíduos (sobre) vivem de modo desumano.

Como retrato atual das prisões brasileiras, o Ministro Ricardo Lewandowski, em voto proferido no RE 592.581/RS, aduz:

Ouso assinalar, desde logo, que até o mais desinformado dos cidadãos possui algum
conhecimento acerca do quadro de total falência do sistema carcerário brasileiro, o
que faz com que tal problema ultrapasse as fronteiras do Rio Grande do Sul. O senso
comum não nega - ao contrário, reafirma - que o histórico das condições prisionais
no Brasil é de insofismável precariedade. Nesse contexto, são recorrentes os relatos
de sevícias, torturas físicas e psíquicas, abusos sexuais, ofensas morais, execuções

\footnotetext{
${ }^{4}$ Para a presente pesquisa, adota-se a linha universalista dos direitos humanos, a qual estabelece que deve haver
} um mínimo ético irredutível para que uma pessoa possa viver com dignidade (PIOVESAN, 2006, p. 12-14) 
sumárias, revoltas, conflitos entre facções criminosas, superlotação de presídios, ausência de serviços básicos de saúde, falta de assistência social e psicológica, condições de higiene e alimentação sub-humanas nos presídios. (...) Os fatores negativos acima descritos, fartamente veiculados pelos meios de comunicação, longe de representarem qualquer sensacionalismo midiático, revelam o cenário dantesco a que são submetidos os presidiários em nosso país. Abundam relatos de detentos confinados em contêineres expostos ao sol, sem instalações santitárias; de celas previstas para um determinado número de ocupantes nas quais se instalam diversos “andares” de redes para comportar o dobro ou o triplo da lotação prevista; de total promiscuidade entre custodiados primários e reincidentes e, ainda, entre presos provisórios e condenados definitivamente. (BRASIL, 2015, p. 19-20).

O voto do Ministro Ricardo Lewandowski retrata, fielmente, a atual situação do sistema penitenciário brasileiro, demonstrando que a população que lá se encontra é invisível aos olhos da maioria da população brasileira e da classe política, que não atua no sentido de melhorar tal situação.

Segundo o mais recente Levantamento Nacional de Informações Penitenciárias (2016), a população carcerária brasileira era de 726.712 (setecentos e vinte e seis mil, setecentos e doze) presos. Deste total

689.510 pessoas que estão em estabelecimentos administrados pelas Secretarias Estaduais de Administração Prisional e Justiça, o sistema penitenciário estadual; 36.765 pessoas custodiadas em carceragens de delegacias ou outros espaços de custódia administrados pelas Secretarias de Segurança Pública; e 437 pessoas que se encontram nas unidades do Sistema Penitenciário Federal, administradas pelo Departamento Penitenciário Federal. (BRASIL, 2016)

Atualmente, o Brasil ocupa a $3^{\text {a }}$ posição no ranking do encarceramento, estando abaixo apenas dos EUA, que possui 2.145.100 (dois milhões, cento e quarenta e cinco mil e cem) e da China, com 1.649.804 (um milhão, seiscentos e quarenta e nove mil, oitocentos e quatro) presos.

Importa salientar que, da população carcerária aferida no levantamento nacional de 2016, aproximadamente 292.450 (duzentos e noventa e dois mil, quatro centos e cinquenta) presos teriam o direito ao voto (BRASIL, 2016). Portanto, apesar da situação jurídica em que se encontra, recolhido ao cárcere, o preso provisório, teoricamente, mantém os seus direitos políticos, de votar e ser votado. 


\section{OS DIREITOS POLÍTICOS DOS PRESOS PROVISÓRIOS.}

Não há, no ordenamento jurídico pátrio, previsão que impeça o preso provisório de votar, tampouco de suspensão do seu direito político, visto que esta ocorre somente na hipótese de condenação transitada em julgado. No entanto, a realidade do sistema carcerário vai no sentido contrário, posto que impeça o exercício de participação ativa na democracia, ao indivíduo que esteja cautelarmente preso.

No geral, se diz que a democracia tem mais de 2.500 anos, dado que remonta a ideia grega de participação popular (BITTAR; DE ALMEIDA, 2005), mas ao longo desse tempo ela teve uma história extremamente fragmentada, de maneira que se pode afirmar que as últimas décadas constituem uma exceção histórica, não apenas no sentido de estabilidade, como de prestígio da democracia. Mudou-se o conceito e a percepção de democracia.

A atual concepção de democracia decorreu das Revoluções Liberais, sendo o conceito democrático composto por elementos de igualdade (TOQUECVILLE, 2007), representatividade (KELSEN, 2003), participação (HABERMAS, 2003) e pluralidade (ARON, 1968). Analisar a democracia sem a existência e implementação dessas 4 (quatro) características é deturpar a ideia de Estado Democrático contemporâneo, posto que se faz imperioso admitir a pluralidade dos indivíduos, reconhecendo-lhes a igualdade e permitindolhes escolher os seus representantes, de modo a participarem, efetiva e universalmente, da política do Estado.

\subsection{Breve desenvolvimento conceitual.}

É comumente aceito que os direitos fundamentais de primeira dimensão são decorrentes das revoluções liberais, nas quais se buscavam alcançar os direitos civis e políticos (ROSENFIELD, 2017). Esses direitos têm um viés tipicamente democrático, na medida em que seu foco era a limitação de poder do Estado e a participação popular nas decisões. Cabe apontar, entretanto, que as conquistas das Revoluções Liberais não aconteceram abruptamente, principalmente na Europa, décadas se passaram antes que se consolidassem os ganhos teóricos relevantes para o discurso democrático.

Ainda assim, é indiscutível que as Revoluções Liberais são responsáveis pela consagração do mais básico elemento constitutivo da democracia: a universalidade. É impossível caracterizar um regime como democrático, se ele não assegurar ampla participação 
política (ainda que por meio de representação), o que é uma herança direta das Revoluções Liberais. Toda democracia tem a universalidade como marca distintiva de sua forma de governo, sendo esse um rompimento de paradigma tão significativo, que promove uma ruptura inclusive com a ideia de democracia havida na Grécia antiga.

Até a metade do século XIX, ainda se pensava a democracia em termos de direitos de primeira dimensão e igualdade formal perante a lei. Um Estado podia ser considerado democrático desde que assegurasse a participação política, não fosse opressor e assegurasse o império do Direito na sociedade. Ocorre que, nesse contexto, a democracia não chegava efetivamente a ser exaltada como um modelo a ser buscado, posto que ainda era difícil diferenciar o princípio democrático do próprio Estado de Direito. Só com a difusão do sistema eleitoral é que o próximo passo para o desenvolvimento do pensamento democrático foi dado.

Nesse contexto é que Hans Kelsen (2003) escreve sua obra sobre democracia, discutindo a dissonância existente entre a democracia antiga e a contemporânea. Em tal obra, o jurista apresentará a concepção de que a democracia direta se tornou inviável nas complexas sociedades atuais, de forma que qualquer funcionalidade da democracia só é possível dentro de um sistema que se baseie na representatividade. Segundo Kelsen (2003), não existe democracia sem partidos políticos capazes de organizar as ideologias de forma racional.

Na esteira da catástrofe humanitária da Segunda Guerra e da expansão das ditaduras comunistas, coube a Raymond Aron (1968) consagrar o pluralismo como elemento fundamental da democracia. Para tanto, o autor estabeleceu a diferença entre autoritarismo e totalitarismo, mostrando como a democracia corria risco não apenas quando o Estado excluía o povo da participação decisória, mas também quando o Estado invadia a esfera privada, suprimindo a diversidades típica de uma sociedade democrática.

Por fim, ainda no século XX, Jürgen Habermas (2003) apresentou sua Teoria Procedimental-Discursiva, na qual dará destacou o caráter formal da democracia, dizendo que o que caracteriza uma norma democrática (ou autoritária) não é seu conteúdo, mas o fato de que seja possibilitado aos seus destinatários serem (ou não) autores da decisão. Para assegurar tal participação, necessária a existência de uma esfera pública na qual seja viabilizado o discurso dos participantes no processo decisório típico da democracia. 
4.2 Democracia e o voto.

Segundo Aristóteles, as formas de governo podem ser classificadas como monarquia, aristocracia e democracia. Apesar de haver uma ideia central de cada forma de governo ainda ser a mesma, Paulo Bonavides faz uma análise contemporânea, ao afirmar que:

A monarquia, a primeira dessas formas, representa, segundo Aristóteles, o governo de um só. Atende o sistema monárquico à exigência unitária na organização do poder político, exprimindo uma forma de governo na qual se faz mister o respeito das leis. A aristocracia, como segunda forma, na classificação de Aristóteles, significa o governo de alguns, o governo dos melhores. Na etimologia da palavra "aristocracia” deparamo-nos já com a idéia de força. Essa raiz evolve naturalmente para a acepção de força da cultura, força da inteligência, força entendida de modo qualitativo, força, por conseguinte, dos melhores, dos que tomam as rédeas do governo. A exigência de todo governo aristocrático deve ser, segundo Aristóteles, a de selecionar os mais capazes, os melhores. Quanto ao terceiro tipo de governo, contido nessa classificação, Aristóteles fá-lo corresponder à Democracia, governo que deve atender na sociedade aos reclamos de conservação e observância dos princípios de liberdade e de igualdade. (2000, p. 248/249).

A Constituição Federal de 1988 define a democracia brasileira como semidireta, ou seja, como uma democracia representativa e com mecanismos de participação direta (LOPES, 2006, p.28). O exercício da participação do cidadão pode ser encontrado no artigo $14^{\circ}$ da Constituição Federal vigente, prevendo que “A soberania popular será exercida pelo sufrágio universal e pelo voto direto e secreto, com valor igual para todos, e nos termos da lei” (BRASIL, 1988).

Ao analisar o papel do povo na democracia, pelo menos no âmbito ideológico, Kelsen afirma que esta é:

uma forma de Estado e de sociedade em que a vontade geral, ou sem tantas metáforas, a ordem social, é realizada por quem está submetido a essa ordem, isto é, pelo povo. Democracia significa identidade entre governantes e governados, entre sujeito e objeto do poder, governo do povo sobre o povo. (2003, p. 35).

Pode-se afirmar que uma das formas de participação do povo na democracia semidireta se dá por meio do sufrágio, sendo este o elemento que reconhece a participação direta (ou indireta) dos cidadãos na vida pública (BONAVIDES, 2000, p. 293). Durante o século XIX, iniciou-se uma grande movimentação, das mais diversas classes sociais, para transformar o 
sufrágio em universal, livre de qualquer restrição, com o escopo de conduzir a democracia à sua plenitude.

Na Inglaterra, a restrição foi abolida com a reforma trabalhista de 1948; na França, a Constituição de 1973 adotou o sufrágio universal, mas sua efetivação só ocorreu em 1848; e nos Estados Unidos, a consagração do sufrágio universal se deu com a adoção de duas emendas constitucionais, a $15^{\mathrm{a}}$, em 1870, e a $19^{\mathrm{a}}$, em 1920.

No Brasil, a universalidade do sufrágio está prevista constitucionalmente no caput do artigo $14^{\circ}$ da $\mathrm{CF} / 88$, o qual determina que o voto deverá ser direto e secreto, sendo estas duas características complementares à universalidade, visando, em última análise, ao exercício livre da democracia.

Nesse sentido, Paulo Bonavides afirma que:

O voto secreto, garantia efetiva do princípio democrático, constitui um complemento do sufrágio universal. Daí também seu caráter obrigatório. A inobservância do segredo acarreta, pois, a anulação do voto, conforme dispõe a esse respeito a legislação eleitoral da maior parte dos Estados que adotam o sufrágio universal. Mas antes que se obtivesse nos sistemas democráticos semelhante compreensão, já hoje pacífica, gravou-se ardente polêmica, com argumentos tanto favoráveis como adversos ao voto secreto. (BONAVIDES, 2000, p. 306/307).

Pode-se afirmar, portanto, que o direito ao voto é um dos maiores instrumentos de participação popular na democracia; a restrição a este direito, contrariando a Constituição Federal e a legislação ordinária, constitui-se grave atentado contra o Estado Democrático de Direito.

4.2 Os direitos políticos do preso provisório no Brasil.

Como verificado anteriormente, o ordenamento processual penal brasileiro prevê dois gêneros de prisão, a prisão pena e a prisão cautelar, sendo esta a que tem por objetivo, unicamente, resguardar o trâmite do processo penal, enquanto aquela é decorrente de uma sentença penal condenatória transitada em julgado.

A Lei $n^{0} 7.210 / 84$ prevê, no artigo $3^{\circ}$, que “ao condenado e ao internado serão assegurados todos os direitos não atingidos pela sentença ou pela lei”. No mesmo sentido é o disposto no artigo $38^{\circ}$ do Código Penal, ao afirmar que “o preso conserva todos os direitos não 
atingidos pela perda da liberdade, impondo-se a todas as autoridades o respeito à sua integridade física e moral” (BRASIL, 1940).

Da leitura dos dois dispositivos acima, pode-se afirmar que preso condenado mantém todos os direitos que lhe são garantidos antes do trânsito em julgado da condenação, ressalvados aqueles incompatíveis com a situação de encarceramento e os decorrentes do efeito da sentença penal condenatória.

Nesse sentido, Avena afirma que

Ressalvadas as restrições decorrentes da própria sentença penal e os efeitos da condenação previstos na Constituição Federal e na legislação infraconstitucional, o condenado mantém incólume todos os direitos que lhe assistiam antes do trânsito em julgado da decisão condenatória. (AVENA, 2017, p. 15).

É certo que a condição de preso acarretará a restrição de alguns direitos decorrentes da condenação, notadamente à liberdade de locomoção, de forma livre, e à ampla e irrestrita comunicação. No que tange aos direitos políticos, o artigo $15^{\circ}$, inciso III, da Constituição Federal de 1988 determina a imediata e obrigatória suspensão dos direitos políticos do condenado. Esta restrição irá perdurar durante todo o tempo da condenação e só cessará com o cumprimento ou extinção da pena.

Segundo Avena:

Nos termos do art. 15, III, da Carta de República, a condenação criminal transitada em julgado, enquanto perdurarem seus efeitos, acarreta automática e obrigatoriamente a suspensão dos direitos políticos do condenado. A suspensão cessa apenas com o cumprimento ou a extinção da pena, independendo de reabilitação ou de prova de reparação de danos. (AVENA, 2017, p. 17/18).

Ocorre que, em tese, os direitos de votar e ser votado, do preso provisório, não são atingidos, especialmente porque não há expressa previsão legal nesse sentido. Fala-se que, “em tese”, estes direitos não serão tolhidos, pois, “em muitos casos, torna-se inviável a instalação de sessões eleitorais no interior dos presídios e essa circunstância resulta em prejudicar o direito ao sufrágio.” (AVENA, 2017, p. 18).

O problema que se discute aqui reside na implementação deste direito, que o Estado nega ao preso provisório e, por via de consequência, o impede de participar do processo democrático. Apesar de não existir a suspensão dos direitos políticos do preso provisório, este não pode exercê-lo, por indubitável incapacidade do Estado de garantir o mínimo irredutível ao preso, o exercício dos seus direitos humanos. Assim, o Estado, ao se omitir de promover a real 
aplicação do sufrágio universal, age como molestador de um direito fundamental, previsto na CF/88.

4.3 Resolução n ${ }^{\circ} 23.219$ do TSE: Entre a inefetividade e negativa do direito ao voto.

Apesar de o texto constitucional ser claro acerca da suspensão dos direitos políticos apenas aos presos condenados com sentença penal condenatória transitada em julgado, somente em 02 de março de 2010 o Tribunal Superior Eleitoral editou a Resolução no 23.219, no sentido de dar eficácia ao direito de voto do preso provisório. A Resolução determina a criação de seções eleitorais nos estabelecimentos penais, para garantir o direito de votar, ao preso não condenado.

\footnotetext{
Art. $1^{\circ}$. Os Juízes Eleitorais, sob a coordenação dos Tribunais Regionais Eleitorais, criarão seções eleitorais especiais em estabelecimentos penais e em unidades de internação de adolescentes, a fim de que os presos provisórios e os adolescentes internados tenham assegurado o direito de voto, observadas as normas eleitorais e as normas específicas constantes desta resolução.

Parágrafo único. Para efeito desta resolução, consideram-se:

I - presos provisórios aqueles que, apesar de recolhidos a estabelecimento de privação de liberdade, não possuírem condenação criminal transitada em julgado;

II - adolescentes internados os menores de 21 e os maiores de 16 anos submetidos à medida socioeducativa de internação ou à internação provisória;

III - estabelecimentos penais todos os estabelecimentos onde haja presos provisórios recolhidos;

IV - unidades de internação todas as unidades onde haja adolescentes internados. (BRASIL, 2010).
}

Além de determinar a criação de seções eleitorais nos estabelecimentos penais, a Resolução $n^{\circ} 23.219$ condiciona a criação da seção eleitoral à existência de, no mínimo. 20 (vinte) eleitores. Dispõe o artigo $12^{\circ}$ : “As seções eleitorais serão instaladas nos estabelecimentos penais e nas unidades de internação com, no mínimo, 20 eleitores aptos a votar” (BRASIL, 2010).

A resolução prevê, ainda, o impedimento para o exercício do voto, ao preso que, no dia da eleição, tiver contra si uma sentença penal condenatória transitada em julgado, conforme consta no artigo $16^{\circ}$ : "Fica impedido de votar o preso que, no dia da eleição, tiver contra si sentença penal condenatória com trânsito em julgado” (BRASIL, 2010). Este impedimento 
decorre da suspensão automática e obrigatória dos direitos políticos, com o trânsito em julgado da sentença penal condenatória.

Segundo dados dos 27 Tribunais Regionais Eleitorais, estariam aptos a votar, na eleição de 2014, 7.855 (sete mil, oitocentos e cinquenta e cinco) presos, perfazendo um total de 3,4\% da população de presos provisórios (BRASIL, 2016). Para atender a esta demanda, foram instaladas 162 (cento e sessenta e duas) seções especiais de votação. Nos estados do Pará, Paraíba, Rio Grande do Norte, Sergipe, Rio de Janeiro, Mato Grosso, Mato Grosso do Sul, Paraná e Rondônia, os presos não poderão votar.

Desse modo, a Resolução do TSE não abrange os estabelecimentos penais ou unidades de internação que não possuem o número mínimo estabelecido, o que, claramente, afronta o direito constitucional ao voto do preso provisório. Há, no caso, uma Resolução de um órgão jurisdicional em total desconformidade com as normas constitucionais, o que causa uma afronta aos direitos fundamentais do preso e ao Estado Democrático de Direito, visto que o indivíduo que está, apenas cautelarmente, com a sua liberdade tolhida, se vê impedido de participar do processo eleitoral de escolha dos seus representantes.

\section{CONCLUSÃO.}

O modelo democrático brasileiro depende estritamente do sufrágio universal e secreto dos cidadãos, os quais são responsáveis por eleger os representes políticos e, consequentemente, as políticas públicas que serão aplicadas no país após cada eleição. Sabe-se, ainda, que os presos com sentença penal condenatória transitada em julgado têm seus direitos políticos suspensos até o termo final do apenamento.

De acordo com os dados levantados, o Brasil ocupa a terceira posição dentre os países de maior população carcerária no mundo, ficando atrás apenas dos Estados Unidos e da China. A população carcerária brasileira é de 726.712 (setecentos e vinte e seis mil, setecentos e doze) presos, deste total, 40\%, aproximadamente 290.285 (duzentos e noventa mil, duzentos e oitenta e cinco), são presos provisórios, que ainda não foram julgados. Entende-se que a suspensão dos direitos políticos só atinge o preso com sentença penal condenatória transitada em julgado, permanecendo, os referidos direitos, assegurados aos presos provisórios.

No entanto, apesar dos presos provisórios não terem os seus direitos políticos suspensos, estes não podiam ser exercidos de fato, diante da situação de encarceramento que viviam. Somente em 2010, o Tribunal Superior Eleitoral editou a Resolução no 23.219, que determinava a instalação, nos estabelecimentos penais, de seções estaduais, para garantir o 
direito ao voto do preso provisório. Além de instituir as normas para a criação das seções, a resolução também apresentou os requisitos para que a seção fosse instalada, sendo necessário, no mínimo, vinte presos aptos a votar. Este requisito acabou por impedir que vários estabelecimentos penais recebessem a seção especial.

A falta de instalação de seção especial para atender à população carcerária de presos provisórios, que, em 2014, era de, aproximadamente, 249.000 (duzentos e quarenta e nove mil) presos, suprime, de forma ilegal e abusiva, um direito constitucional assegurado, ferindo a dignidade da pessoa humana e excluindo o indivíduo do processo democrático. Por fim, conclui-se que a supressão ilegal dos direitos políticos dos presos provisórios acaba por marginalizá-los ainda mais, uma vez que os torna invisíveis aos olhos da classe política.

\section{REFERÊNCIAS}

ARON, Raymond. Democracia y totalitarismo. 1968.

AVENA, Norberto. Execução Penal. São Paulo: Gen Método, 2017.

BADARÓ, Gustavo Henrique. Processo Penal. São Paulo: Editora Revista dos Tribunais, 2015.

BITTAR, Eduardo Carlos Bianca; DE ALMEIDA, Guilherme Assis. Curso de filosofia do direito. Atlas, 2005.

BONAVIDES, Paulo. Ciência Política. São Paulo: Malheiros, 2000.

BRASIL. Código Penal. Brasília, DF: Senado Federal: Centro Gráfico, 1988.

BRASIL. Constituição da República Federativa do Brasil. Brasília, DF: Senado Federal: Centro Gráfico, 1988.

BRASIL. Lei de Execução Penal (Lei no 7.210/84). Brasília, DF: Senado Federal: Centro Gráfico, 1988. Disponível em: < http://www.planalto.gov.br/ccivil_03/Leis/17210.htm> Acesso em: 29 mar. 2018. 
BRASIL. Ministério da Justiça. Departamento Penitenciário Nacional. Censo 2014. Disponível em: < http://www.justica.gov.br/news/mj-divulgara-novo-relatorio-do-infopen-nesta-tercafeira/relatorio-depen-versao-web.pdf> Acesso em: 3 dez. 2017.

BRASIL. Ministério da Justiça. Departamento Penitenciário Nacional. Censo 2016. Disponível em: $\quad<$ http://depen.gov.br/DEPEN/noticias-1/noticias/infopen-levantamento-nacional-deinformacoes-penitenciarias-2016> Acesso em: 8 dez. 2017.

BRASIL. Supremo Tribunal Federal. Recurso Extraordinário $\mathbf{n}^{\mathbf{0}}$ 592.581. Reclamante: Ministério Público do Estado do Grande do Sul. Reclamado: Estado do Rio Grande do Sul. Relator: Ministro Ricardo Lewandowski. Disponível em: < http://www.stf.jus.br/arquivo/cms/noticiaNoticiaStf/anexo/592581.pdf> Acesso em: 29 mar. 2018.

BRASIL. Tribunal Superior Eleitoral. Resolução no 23.219 de 2010. Dispõe sobre a instalação de seções eleitorais especiais em estabelecimentos penais e em unidades de internação e dá outras providências. Disponível em: <http://www.tse.jus.br/legislacaotse/res/2010/RES232192010.htm> Acesso em: 02 abr. 2018.

BRASIL. Código de Processo Penal. Brasília, DF: Senado Federal: Centro Gráfico, 1940. Disponível em: <http://www.planalto.gov.br/ccivil_03/decreto-lei/Del3689Compilado.htm> Acesso em: 04 jul. 2018.

DOTTI, René Ariel. A crise do sistema penal. Vol. 768. São Paulo: Revista dos Tribunais, 1999.

HABERMAS, Jürgen; SIEBENEICHLER, Flávio Beno. Direito e democracia: entre facticidade e validade. Rio de Janeiro: Tempo Brasileiro, 2003.

KELSEN, Hans. A democracia. São Paulo: Martins Fontes, 2003.

PACELLI, Eugênio. Processo Penal. São Paulo: Editora Gen Atlas, 2017.

PACI, Maria Fernanda. Sistema prisional brasileiro. ETIC - encontro de iniciação científicaISSN 21-76-8498, v. 9, n. 9, 2014. 
PIOVESAN, Flávia. Direitos humanos: desafios da ordem internacional contemporânea. Direitos humanos, v. 1, p. 15-37, 2006.

ROSENFIELD, Denis Lerrer. O que é democracia. Brasiliense, 2017.

TOCQUEVILLE, Alexis de. Da democracia da América. São João do Estoril: Principia, 2007. 